\title{
Bilateral macular injury from a green laser pointer
}

This article was published in the following Dove Press journal:

Clinical Ophthalmology

29 October 2013

Number of times this article has been viewed

\section{Ali Dirani ${ }^{1,2}$ \\ Elias Chelala ${ }^{2}$ \\ Ali Fadlallah ${ }^{1,2}$ \\ Rafic Antonios' \\ George Cherfan'}

'Beirut Eye Specialist Hospital,

${ }^{2}$ Faculty of Medicine, Saint-Joseph

University, Beirut, Lebanon
Correspondence: Ali Fadlallah Faculty of Medicine, Saint-Joseph University, PO Box | |6-53 | I,

Beirut, Lebanon

Tel +96| 7 |388893

Email fadlallah2000@hotmail.com
Abstract: We report the case of a 13-year-old boy who had a bilateral macular injury after playing with a green laser pointer for a duration of 1 minute. Clinical examination revealed a decrease in visual acuity and macular injury in both eyes, and imaging investigations revealed a bilateral macular lesion due to exposure to the laser pointer. At 3 months' follow up, visual function had improved but remained partially impaired. This case emphasizes the importance of cautious and appropriate use of laser pointer devices because of the potential vision-threatening hazards induced by mishandling of these devices.

Keywords: green laser pointer, bilateral, macular injury

\section{Introduction}

Lasers produce a beam of light that is coherent, monochromatic, and unidirectional, and can converge most of its radiant power over small areas, even at great distances. Laser pointers are useful ubiquitous devices used in everyday situations, especially in the educational environment. They are also used frequently by children as toys. Their potential to cause retinal damage is a matter of concern, and manufacturers warn against injudicious ocular exposure to laser light. Low-energy green laser pointers are generally considered to be safe devices and their potential to cause retinal damage is questionable. Here we report a case of macular damage caused by a green laser pointer in a teenager, along with a brief review of the literature.

\section{Case report}

A 13-year-old boy presented to our clinic complaining of decreased vision in both eyes 1 day after having intentionally gazed directly into the beam of a green laser pointing device (wavelength $532 \mathrm{~nm}$ ), that had a maximum power rating of $5 \mathrm{~mW}$ (US Food and Drug Administration class 3A or IEC class 3R) stated on its labeling. He held the laser $5 \mathrm{~cm}$ away from his eyes for an estimated 30-60 seconds. Prior to this incident, the boy had reported no visual complaints. His last ocular examination had revealed visual acuity of 20/20 in both eyes.

Current examination revealed best-corrected visual acuity of 20/50 in the right eye and 20/30 in the left eye. Anterior segments were normal in both eyes. Fundus examination showed bilateral, yellowish, oval-shaped, drusenoid-like lesions with attenuation of the foveal reflex (Figure $1 \mathrm{~A}$ and $\mathrm{B}$ ).

Imaging studies were done on presentation to our practice 18 hours after exposure to the laser device. Optical coherence tomography (3D OCT; Topcon, Tokyo, Japan) 

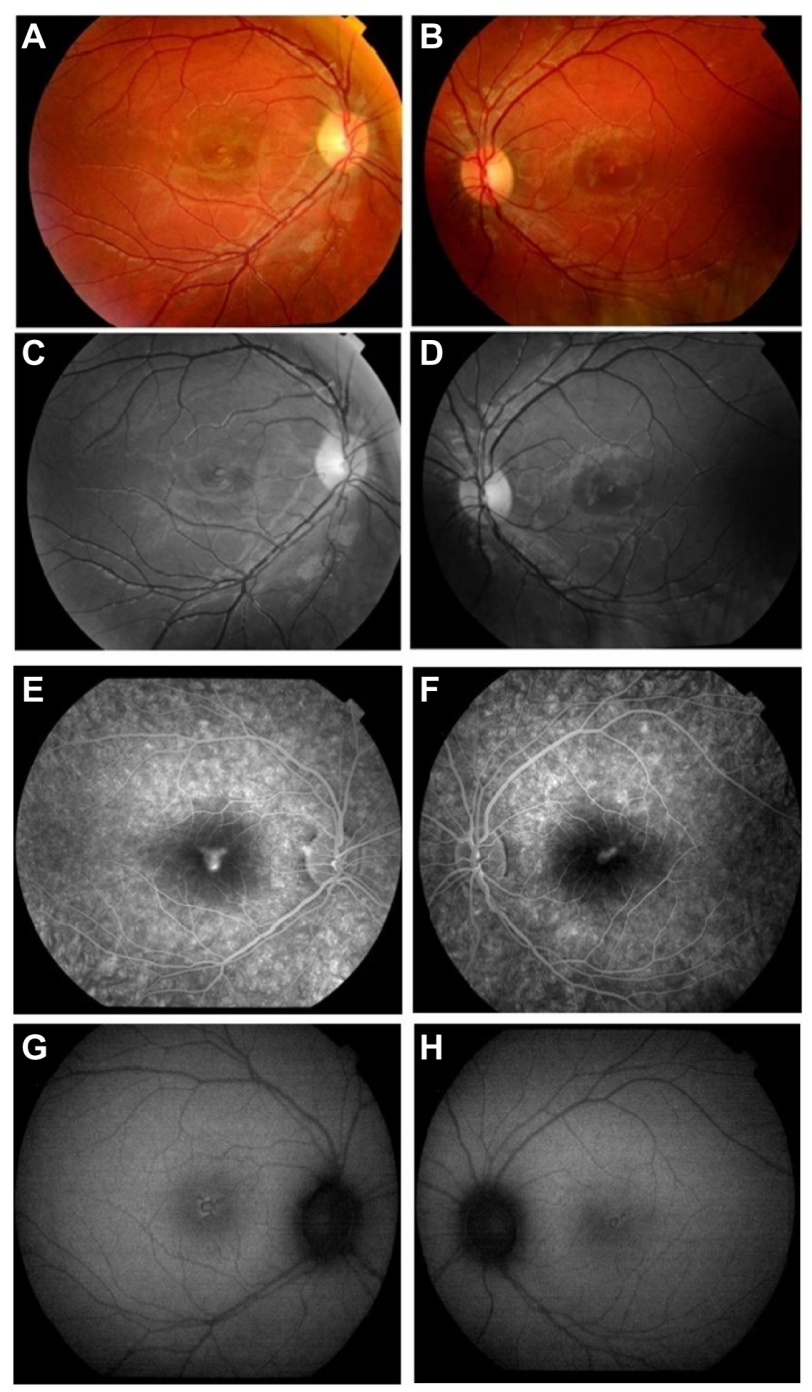

Figure I (A and B) Fundus photographs showing yellowish, oval-shaped drusenoidlike lesion with attenuation of the foveal reflex in both eyes. (C and D) Red-free fundus photographs showing heterogeneous foveal lesions. (E and F) Fluorescein angiogram showing early foveal hyperfluorescence with late ill-defined leakage in right eye and left eye, respectively. ( $\mathbf{G}$ and $\mathbf{H}$ ) Autofluorescence photos showed heterogeneous hyperfluorescence in the macula of both eyes.

Note: A,C,E, and $\mathbf{G}$ are right eye; $\mathbf{B}, \mathbf{D}, \mathbf{F}$, and $\mathbf{H}$ are left eye. of both eyes showed disruption of the outer retinal layer with nonspecific retinal thickening (Figure 2A and B); red-free photographs demonstrated hypopigmented foveal dots bilaterally (Figure 1C and D); fluorescein angiography showed early foveal hyperfluorescence in both eyes with late ill-defined leakage (Figure 1E and F); and autofluorescence images showed heterogeneous hyperfluorescence in the macula of both eyes (Figure $1 \mathrm{G}$ and H). Finally, a computerized 10-2 visual field threshold test (Humphrey Automated Perimeter; Humphrey Instruments, San Leandro, CA, USA), showed small pericentral scotomata in the right eye and a normal field in the left eye.

The patient was treated with an oral steroid (Prednisone; H.J. Harkins Company, Inc., Grover Beach, CA, USA) $1 \mathrm{mg} /$ $\mathrm{kg}$ for 4 weeks then tapered over 2 months. At 3 months, visual acuity remained impaired but improved to $20 / 30$ in the right eye and 20/25 in the left eye.

At 3 months, optical coherence tomography showed improvement of the retinal thickening in both eyes. The hyperreflective line representing the inner segment/outer segment junction was disrupted in the right eye and the left eye (Figure $2 \mathrm{C}$ and $\mathrm{D}$ ). The visual field improved and no scotoma was detected in the right eye.

\section{Discussion}

Laser pointer devices are a common and essential part of everyday life. This may lead to an increasing number of exposures to this type of laser device. However, there is debate about the ocular risks posed by inadvertent exposure to standard laser pointer devices, with the presence of an actual laser-induced injury often inconclusive or entirely absent in some studies. ${ }^{1-3}$ Literature supporting laser pointer-induced retinal injury has been limited to only a few articles on class $3 \mathrm{~A}$ red laser
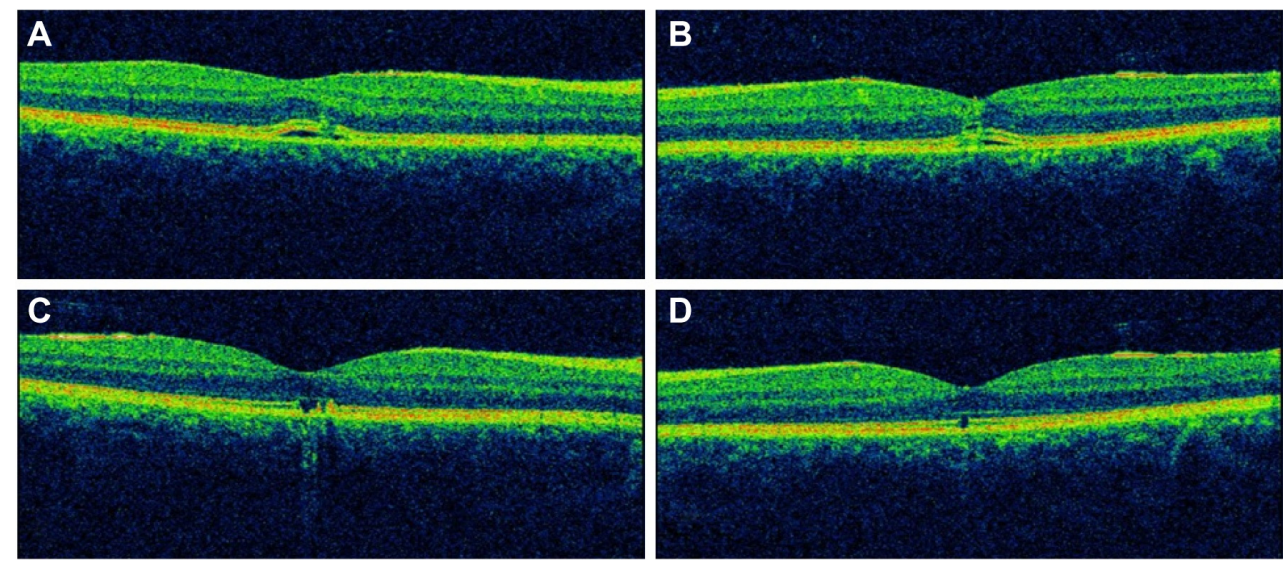

Figure 2 Optical coherence tomography. (A and B) Disruption of the outer retinal layers with nonspecific retinal thickening in both eyes at presentation. (C and D) Disruption of the inner segment/outer segment junction in both eyes, at 3 months after presentation.

Note: $\mathbf{A}$ and $\mathbf{C}$ are right eye; $\mathbf{B}$ and $\mathbf{D}$ are left eye. 


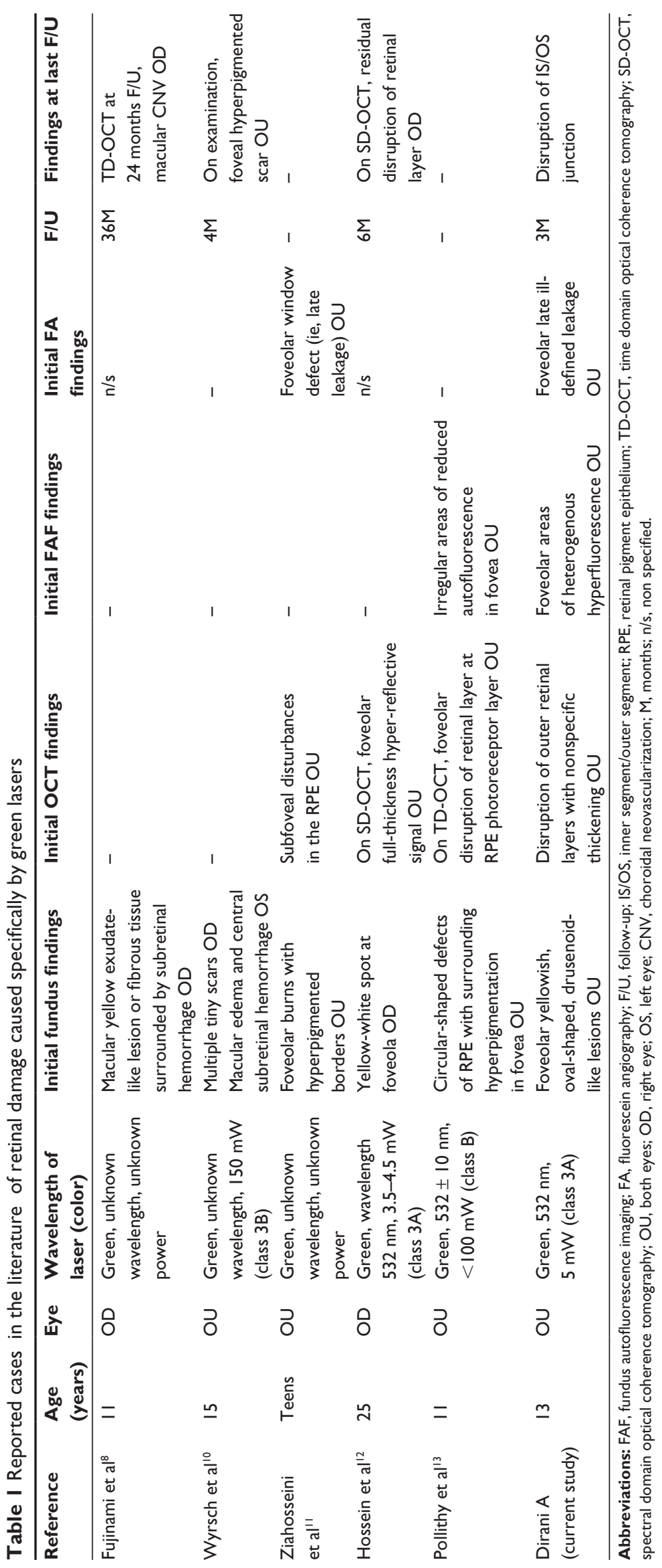


pointers, and even less literature exists on the retinal hazards of class $3 \mathrm{~A}$ green laser pointers. In the literature, retinal lesions induced by laser pointers (both green and red devices) include foveal granularity, perifoveal drusenoid-like deposits, or foveal ring-shaped hypopigmented lesions, subretinal hemorrhage, vitreous or chorioretinal hemorrhage, retinal edema, scars in the pigment epithelium, and rarely choroidal neovascularization. ${ }^{4}$ Comparison of the retinal findings in our patient with those of other reported cases in the literature caused specifically by green lasers are listed in Table 1.

According to Barkana and Belkin, several factors contribute to laser-related retinal damage, and these can be divided into two categories, ie, laser-related factors (wavelength of the radiation; pulse duration; and energy level of the beam) and patient-related factors (size of the pupil, with injury being more severe in larger pupil sizes; degree of retinal pigmentation, with dark-skinned individuals suffering more severe injury than light-skinned ones; proximity of incident beam to the fovea; and refraction status, with damage being more severe in emmetropic eyes due to the laser beam being more focused on the retina). ${ }^{5}$ Also, experimental studies that have evaluated the clinical and histopathologic effects of laser pointers in eyes undergoing enucleation for melanoma concluded that green laser pointers $(490-575 \mathrm{~nm})$ are more damaging to the retina than red laser pointers $(635-750 \mathrm{~nm}){ }^{1,6}$

Laser-induced damage to the retina is even more concerning in children and infants than in adults. Whereas adults terminate accidental laser pointer exposure in less than 0.25 seconds by pupil, blink, and aversion responses, ${ }^{7}$ children have been reported to display "unusual" behavior, ie, staring for a prolonged period of time into the laser beam without blinking or averting the eye. ${ }^{8}$

Current medical therapy for retinal injury is mainly limited to corticosteroids on an undetermined regimen and has variable results. ${ }^{5}$ Final visual acuity ranges from 20/20 to $20 / 60$ vision, and this depends on the size and location of the macular lesion. ${ }^{4}$

In recent years, cheap laser pointers are increasingly being used as toys for children. While shrinking in size, handheld laser pointers are becoming increasingly more powerful, and safety is becoming a public health issue. ${ }^{9}$

Clinical Ophthalmology

\section{Publish your work in this journal}

Clinical Ophthalmology is an international, peer-reviewed journal covering all subspecialties within ophthalmology. Key topics include: Optometry; Visual science; Pharmacology and drug therapy in eye diseases; Basic Sciences; Primary and Secondary eye care; Patient Safety and Quality of Care Improvements. This journal is indexed on Submit your manuscript here: http://www.dovepress.com/clinical-ophthalmology-journal
The potential vision-threatening hazards caused by mishandling laser pointers, even class $3 \mathrm{~A}$ lasers, emphasize the importance of cautious and appropriate use of these devices. Recommendations regarding the purchase and use of these devices are being reconsidered. Further restrictions on their sale and use by the general public will require more than simple recommendations; legislation will have to be passed and enforced by governmental bodies.

\section{Disclosure}

The study did not receive any external funding. None of the authors has any proprietary, commercial, or financial interest in any of the products mentioned in this paper.

\section{References}

1. Robertson DM, Lim TH, Salomao DR, Link TP, Rowe RL, McLaren JW. Laser pointers and the human eye: a clinicopathologic study. Arch Ophthalmol. 2000;118(12):1686-1691.

2. Mensah E, Vafidis G, Marshall J. Laser pointers: the facts, media hype, and hysteria. Lancet. 1998;351(9111):1291.

3. Van Norren D, Keunen JE, Vos JJ. [The laser pointer: no demonstrated danger to the eyes]. Ned Tijdschr Geneeskd. 1998;142(36):1979-1982. Dutch.

4. Turaka K, Bryan JS, Gordon AJ, Reddy R, Kwong HM Jr, Sell CH. Laser pointer induced macular damage: case report and mini review. Int Ophthalmol. 2012;32(3):293-297.

5. Barkana Y, Belkin M. Laser eye injuries. Surv Ophthalmol. 2000;44(6): 459-478.

6. Robertson DM, McLaren JW, Salomao DR, Link TP. Retinopathy from a green laser pointer: a clinicopathologic study. Arch Ophthalmol. 2005;123(5):629-633.

7. Mainster MA, Timberlake GT, Warren KA, Sliney DH. Pointers on laser pointers. Ophthalmology. 1997;104(8):1213-1214.

8. Fujinami K, Yokoi T, Hiraoka M, Nishina S, Azuma N. Choroidal neovascularization in a child following laser pointer-induced macular injury. Jpn J Ophthalmol. 2010;54(6):631-633.

9. Silver Spring. Consumer health information: illuminating the hazards of powerful laser products. Food and Drug Administration; 2009. Available from: http://www.fda.gov/ForConsumers/ConsumerUpdates/ ucm166649.htm. Accessed September 22, 2013.

10. Wyrsch S, Baenninger PB, Schmid MK. Retinal injuries from a handheld laser pointer. $N$ Engl J Med. 2010;363(11):1089-1091.

11. Ziahosseini K, Doris JP, Turner GS. Laser eye injuries. Maculopathy from handheld green diode laser pointer. BMJ. 2010;340:c2982.

12. Hossein M, Bonyadi J, Soheilian R, Soheilian M, Peyman GA. SD-OCT features of laser pointer maculopathy before and after systemic corticosteroid therapy. Ophthalmic Surg Lasers Imaging Off J Int Soc Imaging Eye. 2011;42;135-e138.

13. Pollithy S, Ach T, Schaal KB, Dithmar S. [Acute bilateral impaired vision with central scotoma in an 11-year-old boy]. Ophthalmol Z Dtsch Ophthalmol Ges. 2012;109(9):907-910. German.

\section{Dovepress}

PubMed Central and CAS, and is the official journal of The Society of Clinical Ophthalmology (SCO). The manuscript management system is completely online and includes a very quick and fair peer-review system, which is all easy to use. Visit http://www.dovepress.com/ testimonials.php to read real quotes from published authors. 